\title{
Cysteine-Rich Secretory Proteins (CRISP) and their role in mammalian fertilization
}

\author{
Débora J Cohen, Julieta A Maldera, Mariana Weigel Muñoz, Juan I Ernesto, Gustavo Vasen and \\ Patricia S Cuasnicu ${ }^{1}$
}

Instituto de Biología y Medicina Experimental (IBYME-CONICET), Buenos Aires, Argentina.

\begin{abstract}
Epididymal protein CRISP1 is a member of the CRISP (Cysteine-RIch Secretory proteins) family and is involved in sperm-egg fusion through its interaction with complementary sites on the egg surface. Results from our laboratory have shown that this binding ability resides in a 12-amino-acid region corresponding to a highly conserved motif of the CRISP family, named Signature 2 (S2). In addition to this, our results revealed that CRISP1 could also be involved in the previous step of sperm binding to the zona pellucida, identifying a novel role for this protein in fertilization. As another approach to elucidate the participation of CRISP1 in fertilization, a mouse line containing a targeted disruption of CRISP1 was generated. Although CRISP1-deficient mice exhibited normal fertility, CRISP1-defficient sperm presented a decreased level of protein tyrosine phosphorylation during capacitation, and an impaired ability to fertilize both zona-intact and zonafree eggs in vitro, confirming the proposed roles for the protein in fertilization. Evidence obtained in our laboratory indicated that testicular CRISP2 would also be involved in sperm-egg fusion. Competition assays between CRISP1 and CRISP2, as well as the comparison of their corresponding S2 regions, suggest that both proteins bind to common complementary sites in the egg. Together, these results suggest a functional cooperation between CRISP1 and CRISP2 to ensure the success of fertilization.
\end{abstract}

Key words: sperm, gamete fusion, CRISP, egg, fertilization.

\section{INTRODUCTION}

Fertilization in mammals is a complex process that requires the successful completion of a series of orchestrated steps. Although sperm released from the testis are fully differentiated cells, they are not capable of fertilizing an egg. To become competent to fertilize, sperm must undergo several physiological changes during their transit through the male and female reproductive tracts, known as epididymal maturation and capacitation (Yanagimachi, 1994). Once in the proximity of the egg, sperm must pass through the cumulus cells that surround the egg, bind to and penetrate the zona pellucida (ZP) and, finally, fuse with the egg plasma membrane. Most of these events involving cell-tomatrix and cell-to-cell interactions are mediated by specific molecules present in both gametes. One of these proteins is rat epididymal protein CRISP1 (formerly known as DE) (Cameo and Blaquier, 1976) which is the first identified member of the highly conserved Cysteine-RIch Secretory Protein (CRISP) family. The members of this family are characterized by the presence of sixteen conserved cysteine residues, ten of which are clustered in the C-terminal domain of the molecule. Besides CRISP1, other members of the family have been identified in mammals mainly expressed in the male reproductive tract: CRISP2, synthesized in developing spermatids in the testes (Hardy et al., 1988; Kasahara et al., 1989); CRISP3, with a wider tissue distribution than the other CRISPs including reproductive (prostate and ovary) and non-reproductive (salivary gland, pancreas, thymus and colon) organs (Haendler et al., 1993; Kjeldsen et al., 1996; Udby et al., 2005); and the more recently described CRISP4, expressed in the epididymis
(Jalkanen et al., 2005; Nolan et al., 2006). The present article will focus on the results obtained in our laboratory about the involvement of different members of the CRISP family in mammalian sperm-egg interaction.

\section{CRISP1}

Rat CRISP1 (rCRISP1) is synthesized in an androgendependent manner by the proximal segments of the epididymis, and associates with the sperm surface during epididymal maturation (Kohane et al., 1980a and b). Although a substantial amount of rCRISP1 is released during capacitation, part of the protein remains on the sperm surface and migrates to the equatorial segment (Rochwerger and Cuasnicu, 1992). In vitro experiments that showed that exposure of zona-free rat eggs to purified rCRISP1 produced a significant reduction in the percentage of egg penetration without affecting the first step of sperm-egg binding supported the participation of this protein in an event leading to fusion (Rochwerger et al., 1992). These observations also indicate the existence of complementary sites on the egg that were subsequently localized over the entire egg surface, with the exception of the area overlying the meiotic spindle (Rochwerger et al., 1992), a region through which fusion rarely occurs. As described for rCRISP1, evidence supports the involvement of both the mouse and the human CRISP1 homologues in gamete fusion through their binding to complementary sites on their corresponding eggs (Cohen et al., 2000; 2001).

Structure-function studies using bacterially-expressed recombinant CRISP1 (recCRISP1) and a series of recombinant

\footnotetext{
' Corresponding author: Patricia S. Cuasnicu, PhD, IBYME-CONICET, Vuelta de Obligado 2490, (1428) Buenos Aires, Argentina, fax: +54 1147862564 , phone: +54 1147832869 , e-mail: cuasnicu@dna.uba.ar
} 
fragments of the protein led us to circumscribe the eggbinding activity of CRISP1 to a region of 45-amino acids (Figure 1). Interestingly, the analysis of this region revealed it contained the two feature motifs of the CRISP family known as Signature 1 (S1) and Signature 2 (S2). In view of this, two synthetic peptides with the amino acid sequences corresponding to S1 and S2 were generated and used in IIF and gamete fusion assays. The results obtained revealed that the egg-binding ability of rCRISP1 resides in the 12 amino acid region corresponding to S2 (Figure 1) (Ellerman et al., 2006). To our knowledge, these results constituted the first evidence describing a functional role for the motif of the CRISP family and succeeded in delimiting the activity of a CRISP protein to such a small region.

In addition to its role in gamete fusion, experiments in which intact rat and mouse ZP-intact eggs were inseminated with capacitated sperm in the presence of either antirCRISP1 or purified rCRISP1 revealed a novel role for the protein in the previous step of sperm-ZP interaction. Indirect immunofluorescence experiments revealed that rCRISP1 is capable of binding to both the $\mathrm{ZP}$ and the egg plasma membrane, suggesting the existence of CRISP1-binding sites on the ZP. Subsequent experiments using recCRISP1 as well as deglycosylated and heat-denatured native CRISP1 showed that this ZP-binding activity resides in the peptidic region of the molecule and depends on its conformation (Busso et al., 2007a). Recent results indicate that hCRISP1, like its rodent homologues, is involved in sperm-ZP interaction (Maldera et al., 2009).

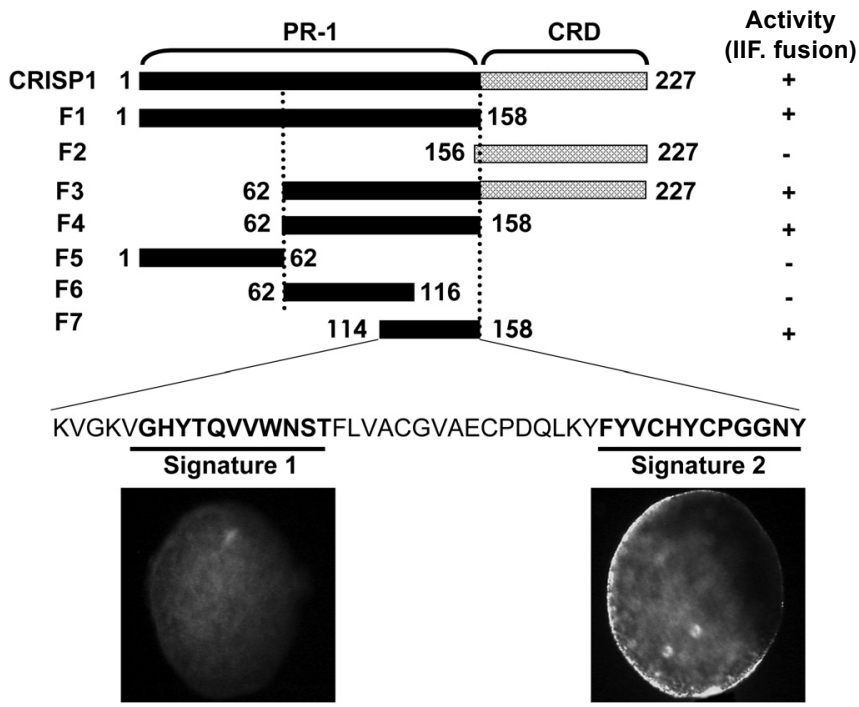

Figure 1. Identification of the egg-binding activity of rat CRISP1: Schematic diagram showing entire recombinant rat CRISP1 and the generated fragments. The numbers indicate the first and last residue for each fragment. Biological activity was evaluated by both indirect immunofluorescence (IIF) and spermegg fusion assays. " + " indicates that the protein/fragments were able to bind to the egg surface and inhibit gamete fusion, while "-" indicates that the fragments neither bound to the egg nor affected sperm-egg fusion. The amino acid sequence shown corresponds to Fragment 7 (F7), which contains Signature 1 and Signature 2 motifs shown in bold. Immunofluorescence images show labeling only in zona-free eggs exposed to the peptide with the amino acid sequence corresponding to Signature 2.
As another approach to elucidate the functional role of CRISP1 in the fertilization process, we generated a mouse line containing a targeted disruption of the Crisp1 gene. Crisp1 $1^{-/-}$ mice were found to be fertile (Figure $2 \mathrm{~A}$ and B) (Da Ros et al., 2008), a result that adds to a growing number of reports of fertile mice lacking proteins proposed to be involved in the fertilization process (Okabe and Cummins, 2007). Based on the observation that many of these fertile "knock out" mice often exhibited other reproductive deficiencies (Baba et al., 2002; Lu and Shur, 1997), Crisp $1^{-/-}$males were evaluated for evidence of changes in different parameters related to reproductive function. Because it has been reported that the presence of CRISP1 during rat sperm capacitation inhibits protein tyrosine phosphorylation (Roberts et al., 2003), we first investigated whether the absence of the protein in the mutant mice produced an increase in the levels of this capacitation-dependent event. Capacitated sperm from Crisp $1^{-/-}$mice exhibited, however, clearly lower levels of tyrosine phosphorylation than controls (Figure 2C), suggesting that CRISP1 plays a regulatory role during mouse sperm capacitation different from that previously proposed for the rat. In spite of the lower levels of tyrosine phosphorylation, Crisp $1^{-/-}$sperm presented normal levels of either spontaneous or progesterone-induced acrosome reaction. This is the first report showing a significant decrease in tyrosine phosphorylation accompanied by normal levels of fertility. These results suggest that protein tyrosine phosphorylation is either not required or, required in low levels such as those observed in our study, to achieve acrosome reaction and normal fertility.
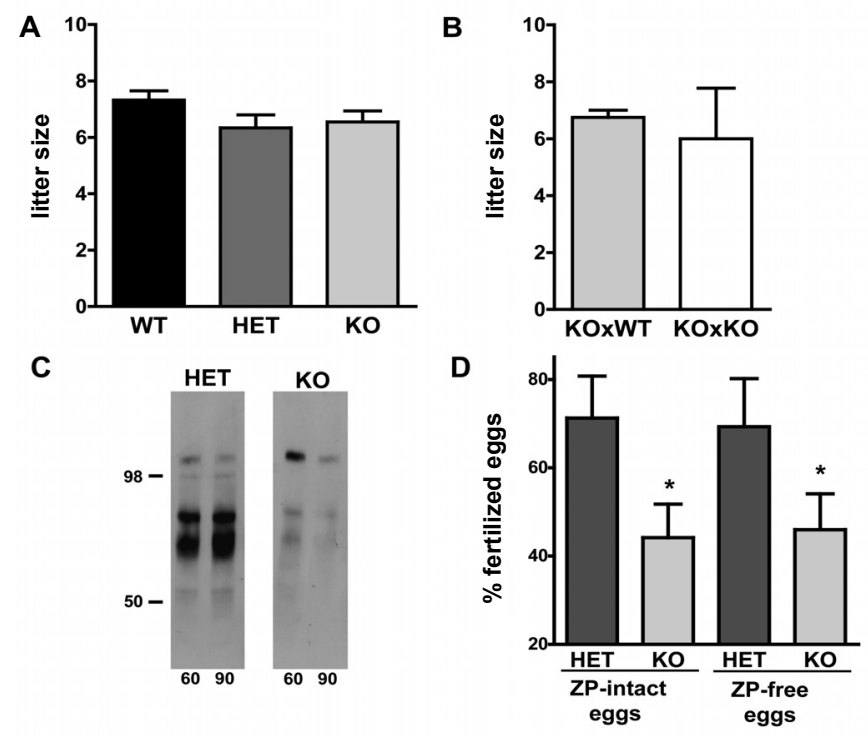

Figure 2. Functional characterization of CRISP1-deficient mice: (A) Fertility of wild type (WT), heterozygous (HET) and Crisp 1 knock out (KO) male mice bred with control females. (B) Fertility of $\mathrm{KO}$ male mice bred with CRISP1-deficient female mice. (C) Epididymal sperm from HET and KO mice were subjected to capacitation, aliquots were removed at 60 and $90 \mathrm{~min}$ and sperm proteins were analyzed by Western blotting using an antiphosphotyrosine monoclonal antibody. (D) Evaluation of fertilizing ability of Crisp 1\% capacitated sperm using ZP-intact or ZP-free eggs. ${ }^{*} \mathrm{p}<0.0002$ 
In vitro fertilization assays showed that Cris $p 1^{-/-}$sperm exhibited a significantly reduced ability to penetrate ZP-intact eggs with no accumulation of sperm in the perivitelline space (Figure 2D). These results are consistent with our recent report proposing a novel role for CRISP1 in sperm-ZP interaction (Busso et al., 2007a). In addition, and in agreement with the postulated role of CRISP1 in gamete fusion, in vitro assays using ZP-free eggs showed a significant reduction in the fusion ability of $\mathrm{Crisp1}^{-/}$sperm (Figure 2D). Moreover, when ZP-free eggs were simultaneously inseminated with Cris $p 1^{+/+}$ and Crisp $1^{-/}$sperm in a competition assay, the mutant sperm exhibited a greater reduction in their fusion ability (Da Ros et al., 2008). Thus, the overall results of the in vitro fertilization studies indicate that sperm lacking CRISP1 present a clear disadvantage in their ability to both interact with the $\mathrm{ZP}$ and fuse with the egg.

The finding that the fusion ability of Crisp1/- sperm was further inhibited by the presence of CRISP1 or CRISP2 during gamete co-incubation (Da Ros et al., 2008), supports the view that another CRISP present on sperm cooperates with CRISP1 during fertilization and might compensate for the lack of CRISP1 in the mutant mice. In this regard, results obtained in our laboratory (and described in the next section) support CRISP2 as the candidate molecule.

\section{CRISP2}

CRISP2 is normally expressed in the testis, in an androgenindependent manner, and is incorporated into the acrosome in round spermatids (Hardy et al., 1988). In rat sperm, CRISP2 was also found as a component of the outer dense fibers of the tail (O'Bryan et al., 1998; O'Bryan et al., 2001), and it has recently been proposed as a regulator of calcium influx through ryanodine receptors during capacitation (Gibbs et al., 2006). Other groups reported the localization of CRISP2 on the surface of spermatogenic cells and postulated that the protein could be responsible for the interaction between germ cells and Sertoli cells (Maeda et al., 1998; Maeda et al., 1999). Results from our group showed that in human and mouse sperm, CRISP2 is an intra-acrosomal protein that remains on sperm after the acrosome reaction, opening the possibility for a role of the protein in fertilization.

The incubation of human and mouse sperm with antiCRISP2 antibodies resulted in an inhibition in egg penetration, supporting its participation in sperm-egg interaction. Interestingly, when zona-intact mouse eggs were used, the significant decrease in the percentage of fertilized eggs was accompanied by an increase in the number of perivitelline sperm per egg (Busso et al., 2007b). These observations indicate that the effect of the antibody was at the sperm-egg membrane interaction level, supporting the specific participation of CRISP2 in gamete fusion. In agreement with this, both rodent and human eggs presented complementary sites for CRISP2 in their surface (Busso et al., 2007b, Busso unpublished observations).

The S2 regions of CRISP1 and CRISP2 differ in only two amino acids, suggesting that both proteins might interact with the same binding sites on the egg. Indirect immunofluorescence competition studies in which zonafree mouse eggs were exposed to both CRISP1 and CRISP2 confirmed the existence of common egg complementary sites for the two proteins (Busso et al., 2007b). These results support both the existence of a functional cooperation between these homologue proteins, and CRISP2 as a candidate molecule to compensate the lack of CRISP1 in the "knock out" mice.

\section{CONCLUSIONS}

The results described in the present work support the involvement of epididymal CRISP1 in protein tyrosine phosphorylation (Figure 3A), sperm-ZP interaction (Figure 3B) and sperm-egg fusion (Figure $3 \mathrm{C}$ ), indicating that although not essential for animal fertility, CRISP1 is a player in the fertilization process. In addition, testicular CRISP2 is also involved in sperm-egg fusion, cooperating with CRISP1 in this step of fertilization (Figure 3D). Altogether, these results support the idea of different functional roles for the same CRISP and the involvement of different CRISPs in the same fertilization event. Considering that sperm are transcriptionally inactive cells, it is likely that this protein functional redundancy in sperm has evolved as a mechanism to ensure the success of the fertilization process.

\section{ACKNOWLEDGEMENTS}

The work described in this review was supported by the World Health Organization (WHO) LID grant (H9/181/R429), the National Research Council (CONICET) grant (PIP 5639), and the National Agency of Scientific and Technological Promotion (ANPCyT) grant (PICT 15-25443) to PSC.

\section{REFERENCES}

BABA D, KASHIWABARA S, HONDA A, YAMAGATA K, WU Q, IKAWA M, OKABE M, BABA T (2002) Mouse sperm lacking cell surface hyaluronidase $\mathrm{PH}-20$ can pass through the layer of cumulus cells and fertilize the egg. J Biol Chem 277:30310-30314.

BUSSO D, COHEN DJ, MALDERA JA, DEMATTEIS A, CUASNICU PS (2007a) A novel function for CRISP1 in rodent fertilization: Involvement in sperm-zona pellucida interaction. Biol Reprod 77:848-854.

Different functional roles for the same CRISP
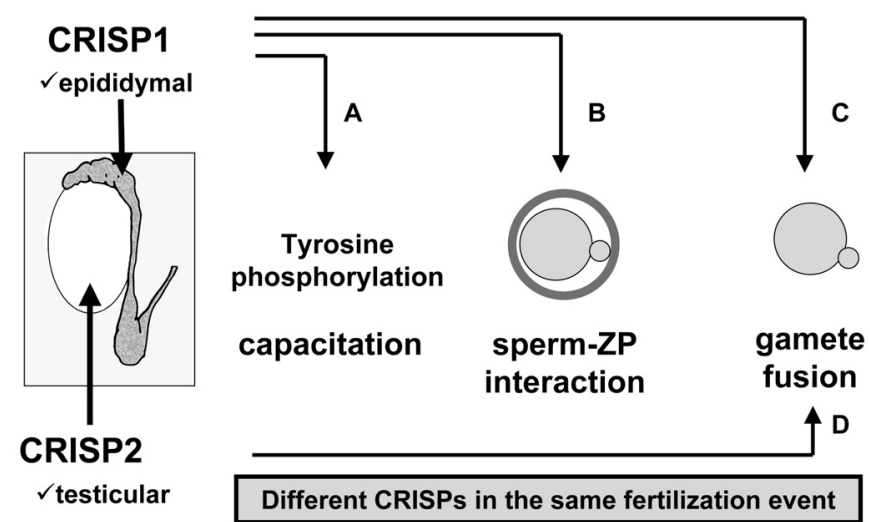

Figure 3. Schematic representation of the roles of CRISP1 and CRISP2 in different steps of fertilization: Epididymal CRISP1 plays a role in protein tyrosine phosphorylation during capacitation (A), sperm-ZP binding (B) and sperm-egg fusion (C) while testicular CRISP2 participates in sperm-egg fusion (D). 
BUSSO D, GOLDWEIC N, HAYASHI M, KASAHARA M, CUASNICU PS (2007b) Evidence for the involvement of testicular protein CRISP2 in mouse sperm-egg fusion. Biol Reprod 76:701-708.

CAMEO MS, BLAQUIER JA (1976) Androgen-controlled specific proteins in rat epididymis. J Endocr 69:317-324.

COHEN DJ, ELLERMAN DA, BUSSO D, MORGENFELD M, PIAZZA A., HAYASHI M, YOUNG ET, KASAHARA M, CUASNICU PS (2001) Evidence that human epididymal protein ARP plays a role in gamete fusion through complementary sites on the surface of the human egg. Biol Reprod 65:1000-1005.

COHEN DJ, ELLERMAN DA, CUASNICU PS (2000) Mammalian spermegg fusion: evidence that epididymal protein DE plays a role in mouse gamete fusion. Biol Reprod 63:462-468.

DA ROS VG, MALDERA JA, WILLIS WD, COHEN DJ, GOULDING EH, GELMAN DM, RUBINSTEIN M, EDDY EM, CUASNICU PS (2008) Impaired sperm fertilizing ability in mice lacking Cysteine-RIch Secretory Protein 1 (CRISP1). Dev Biol 320:12-18.

ELLERMAN DA, COHEN DJ, DA ROS VG, MORGENFELD M, BUSSO D, CUASNICU PS (2006) Sperm protein "DE" mediates gamete fusion through an evolutionarily conserved site of the CRISP family. Dev Biol 297:228-237.

GIBBS GM, SCANLON MJ, SWARBRICK J, CURTIS S, GALLANT E, DULHUNTY AF, O'BRYAN MK (2006) The cysteine-rich secretory protein domain of Tpx-1 is related to ion channel toxins and regulates ryanodine receptor Ca2+ signaling. J Biol Chem 281:4156-4163.

HAENDLER B, KRATZSCHMAR J, THEURING F, SCHLEUNING WD (1993) Transcripts for cysteine-rich secretory protein-1 (CRISP-1; DE/ AEG) and the novel related CRISP-3 are expressed under androgen control in the mouse salivary gland. Endocrinology 133:192-198.

HARDY DM, HUANG TTF, DRISCOLL WJ, TUNG KSK, WILD GC (1988) Purification and characterization of the primary acrosomal autoantigen of guinea pig epididymal spermatozoa. Biol Reprod 38:423-437.

JALKANEN J, HUHTANIEMI I, POUTANEN M (2005) Mouse cysteine-rich secretory protein 4 (CRISP4): a member of the crisp family exclusively expressed in the epididymis in an androgen-dependent manner. Biol Reprod 72:1268-1274.

KASAHARA M, GUTKNECHT J, BREW K, SPURR N, GOODFELLOW PN (1989) Cloning and mapping of a testis-specific gene with sequence similarity to a sperm-coating glycoprotein gene. Genomics 5:527-534.

KJELDSEN L, COWLAND JB, JOHNSEN AH, BORREGAARD N (1996) SGP28, a novel matrix glycoprotein in specific granules of human neutrophils with similarity to a human testis-specific gene product and a rodent sperm-coating glycoprotein. FEBS Lett 380:246-250.

KOHANE AC, CAMEO MS, PIÑEIRO L, GARBERI JC, BLAQUIER JA (1980a) Distribution and site of production of specific proteins in the rat epididymis. Biol Reprod 23:181-187.
KOHANE AC, GONZÁLEZ ECHEVERRÍA F, PIÑEIRO L, BLAQUIER JA (1980b) Interaction of proteins of epididymal origin with spermatozoa. Biol Reprod 23:737-742.

LU QX, SHUR BD (1997) Sperm from beta1,4-galactosyltransferase-null mice are refractory to ZP3-induced acrosome reactions and penetrate the zona pellucida poorly. Development 124:4121-4131.

MAEDA T, NISHIDA J, NAKANISHI Y (1999) Expression pattern, subcellular localization and structure-function relationship of rat Tpx-1, a spermatogenic cell adhesion molecule responsible for association with Sertoli cells. Dev Growth Differ 41:715-722.

MAEDA T, SAKASHITA M, OHBA Y, NAKANISHI Y (1998) Molecular cloning of the rat Tpx-1 responsible for the interaction between spermatogenic and Sertoli cells. Biochem Biophys Res Commun 248:140-146.

MALDERA JA, BUSSO D, CHIRINOS M, GONZÁLEZ RAFFO MF, BLAQUIER JA, LARREA F, CUASNICU PS (2009) Evidence for the participation of human epididymal protein CRISP1 in sperm-zona pellucida interaction. J Androl Suppl. March/April Abstr. 45.

NOLAN MA, WU L, BANG HJ, JELINSKY SA, ROBERTS KP, TURNER TT, KOPF GS, JOHNSTON DS (2006) Identification of rat cysteine-rich secretory protein 4 (Crisp4) as the ortholog to human CRISP1 and mouse Crisp4. Biol Reprod 74:984-991.

O'BRYAN MK, LOVELAND KL, HERSZFELD D, MCFARLANE JR, HEARN MT, DE KRETSER DM (1998) Identification of a rat testis-specific gene encoding a potential rat outer dense fibre protein. Mol Reprod Dev 50:313-322.

O'BRYAN MK, SEBIRE K, MEINHARDT A, EDGAR K, KEAH H, HEARN MT, DE KRETSER DM (2001) Tpx-1 is a component of the outer dense fibers and acosome of rat spermatozoa. Mol Reprod Dev 58:116-125.

OKABE M, CUMMINS JM (2007) Mechanisms of sperm-egg interactions emerging from gene-manipulated animals. Cell Mol Life Sci 64:19451958.

ROBERTS KP, WAMSTAD JA, ENSRUD KM, HAMILTON DW (2003) Inhibition of capacitation-associated tyrosine phosphorylation signaling in rat sperm by epididymal protein crisp-1. Biol Reprod 69:572-581.

ROCHWERGER L, COHEN DJ, CUASNICU PS (1992) Mammalian spermegg fusion: The rat egg has complementary sites for a sperm protein that mediates gamete fusion. Dev Biol 153:83-90.

ROCHWERGER L, CUASNICU PS (1992) Redistribution of a rat sperm epididymal glycoprotein after in vivo and in vitro capacitation. Mol Reprod Dev. 31:34-41.

UDBY L, BJARTELL A, MALM J, EGESTEN A, LUNDWALL A, COWLAND JB, BORREGAARD N, KJELDSEN L (2005) Characterization and localization of cysteine-rich secretory protein 3 (CRISP-3) in the human male reproductive tract. J Androl 26:333-342.

YANAGIMACHI R (1994) Mammalian Fertilization. In: KNOBIL E, NEILL JD (eds) The Physiology of Reproduction. Raven Press. pp:189-317. 